
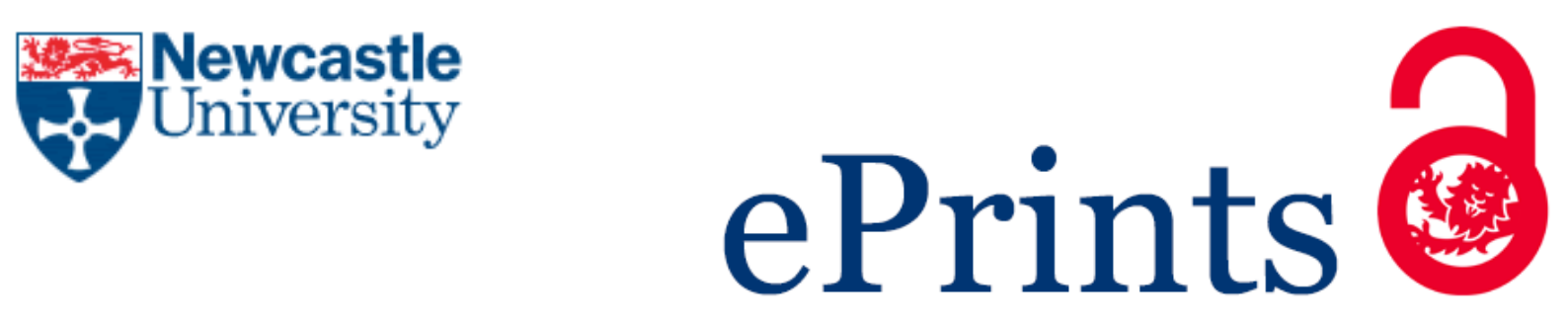

Lindridge AM, Henderson GR, Ekpo AE.

(Virtual) ethnicity, the Internet, and well-being.

Marketing Theory 2015, 15(2), 279-285.

\title{
Copyright:
}

Lindridge AM, Henderson GR, Ekpo AE. (Virtual) ethnicity, the Internet, and well-being. Marketing Theory 2015, 15(2), 279-285. Copyright (C) 2015 The Authors. Reprinted by permission of SAGE Publications.

DOI link to article:

https://doi.org/10.1177/1470593114553328

Date deposited:

$05 / 10 / 2017$

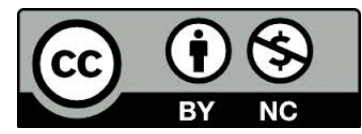

This work is licensed under a Creative Commons Attribution-NonCommercial 3.0 Unported License 


\section{(Virtual) Ethnicity, the Internet and Well-Being}

Andrew Lindridge, The Open University Business School, Michael Young Building, Walton hall, Milton Keynes, MK7 6AA (UK), andrew.lindridge@open.ac.uk

Geraldine Rosa Henderson, Rutgers Business School--Newark and New Brunswick, One Washington Park, Newark, NJ 07102, geraldine.henderson@,rutgers.edu

Akon E. Ekpo, Assistant Professor of Marketing, Western Michigan University, Haworth College of Business, Marketing Department, 1903 W. Michigan Ave., Kalamazoo, MI 49008-5430 USA, akon.ekpo@wmich.edu 


\title{
(Virtual) Ethnicity, the Internet and Well-Being
}

\begin{abstract}
So called Digital Divide studies have focused on the differences in Internet access and usage among various ethno-racial groups attributing these differences to socioeconomic conditions that plague one ethnic group as disadvantaged while casting other ethnic groups as privileged. While these studies possess merit in their assertion of significant differences, the changing availability and thus role of technology within the daily lives of individuals draws questions to how and why these differences manifest in the context of one's well-being. We argue for a broader understanding of how the Internet may be used by consumers to avoid, pursue, and/or resolve one's ethnic identity in their everyday lives.
\end{abstract}

Keywords: Internet, Virtual Ethnicity, Well-being, Identity Project, Acculturation

\section{Introduction}

The internet beyond any reasonable doubt represents the greatest technological change to our lives over the past thirty years. A change that has allowed individuals to form friendships, romances, reconnect with family members over great distances and communicate in ways previously unimaginable beyond the confines of science fiction. Within this change has been a stream of research on whether the internet increases or otherwise our well-being? A report by the British Government in 2013 (Department of Culture, Media and Sport) declared that such was the increase of well-being offered by faster broadband internet that the British Government should do more to accelerate its national coverage in Britain but also increase internet download speeds. This perspective is not unwarranted within previous literature. Indeed, researchers have indicated that the internet and with it opportunities for communicating online leads to increases in an individual's self-esteem and assertion 
(Schmitt, Dayamin and Matthias, 2008; Valkenberg, Peter and Schouten, 2006), with reported increases in adolescent intimacy and friendships through internet usage. Yet considering the relevance of the internet to wellbeing a review of the literature reveals very little research has specifically considered ethnicity. A finding that is more surprising considering research into wellbeing and ethnicity has been considered from differing perspectives of empowerment (Molix and Bettencourt, 2010) and economic power (Nandi and Platt, 2010).

Understanding the role and relevance of the Internet with regards to ethnicity offers researchers an important understanding of these individuals and groups develop a virtual ethnicity and the consequences of this for their wellbeing. In particular in this paper, we argue that the Internet has offered consumers means of constructing, establishing and maintaining virtual ethnicities (Cohen and Prusak, 2001; Henderson et al 2013). Although the emergence of the Internet may have been perceived by Wilson (2002) as a classless, genderless, or an ethnicity-free space, we argue that the Internet is a space which not only fosters these factors, but also one that helps to adapt, construct, and negotiate these aspects of one's self-identity in multiple ways (Foster 2005). Aspects that offer opportunities for wellbeing and for future research.

We explore these themes through three inter-related trajectories. First we discuss the how discrimination encourages individuals to consume through the internet. This is then followed by a discussion on how the internet encourages individuals to seek happiness. The final trajectory discusses how the internet maybe used to construct positive ethnic identities.

\section{Trajectory 1: Avoidance through the use of the Internet}

The Internet allows for those who may feel disenfranchised in their individual locales to develop a broader community of support due to economies of scale. For example, there 
have been numerous events in the media that has highlighted instances of discrimination that occurs in the U.S. marketplace (Crockett, Grier, and Williams 2003; Harris, Henderson, and Williams 2005; Williams, Henderson, and Harris 2001). Given the historic and collective memory of discrimination in offline settings, many ethnic consumers flee to the Internet as a means of avoiding such issues (Ekpo 2012; Williams and Henderson 2011). Consider the research of Ayers and Siegelman (1995) in which they found that while negotiating for a price of a new car, black and female confederates fared far worse than their white male counterparts. In contrast, research conducted by Morton, Zettelmeyer, and Silva-Risso (2005) found that if purchases were made via the Internet, rather than in person, this discriminatory effect diminished. When combined, such studies suggest that it is far less likely for those who conduct business via the Internet, to be discriminated against on the basis of their ethno-racial identity. Consumers then may use the Internet as a means of finding, building, and maintaining much needed community.

For those individuals who in their daily offline lives feel disempowered, escaping to the Internet may provide a means to feel equal or perhaps even greater power in a virtual community. We would therefore invite future research to explore this issue. In particular, what websites offer greater levels of empowerment and wellbeing? What are the characteristics of these websites and how do they conform or otherwise with offline cultural norms? Are these co-constructed websites, blogs or simply commercial websites where comments are invited? Accompanying this research exploring how the individual interprets, engages and understands their internet interactions and the wellbeing consequences of this would also be welcomed.

Paradoxically, the Internet may also exacerbate a resistance to multicultural exposure and interaction. Acculturation literature helps us to understand some of the processes, ideologies, and struggles, individuals may face when confronted with a different culture (for 
example: Askegaard et al., 2005; Berry, 1980; Luna, Ringberg, \& Peracchio, 2008).

Criticisms of acculturation studies lament on the assumed uni-dimensionality of the acculturation process by relegating it to assimilation. However, the Internet provides a space where consumers can progressively develop and reinforce beliefs and values that may be reverberated online (Muniz \& O'Guinn, 2001). For example, consumers in their quest to retain their chosen ethnic identity may use the Internet to resist an ethnic identity they find themselves immersed in offline. Thus escaping to the Internet every time one feels marginalized in the marketplace does not provide the marketplace with the type of feedback mechanism for self-correction. Taken to an extreme conclusion, the Internet could potentially become an even more divisive device for making individuals siloed into their own worlds with little face-to-face interaction. If individuals opt to use these technology-based options instead of local options, it could lead to even greater societal problems.

The social and mental health opportunity costs arising from avoiding discrimination through Internet purchasing remain unclear. Should the ethnically different be encouraged to Internet purchase if this effectively encourages them to withdraw from society? Does the Internet then become a form of Ghettoisation effectively removing the ethnically different from shopping malls that represent the embodiment of the market simply because they can escape discrimination. Or should society view these Internet purchases as the embodiment of society's wider failures to address the very difference and discrimination that motivates an individual or group to withdraw from society? All these questions raise important research issues surrounding well-being and the consumption process within it.

\section{Trajectory 2. Pursuit of Happiness (Hedonic Motivations for Virtual Ethnicity)}

Individuals may also use the Internet for pleasurable pursuits such as finding similar others with similar interests via virtual communities (Muniz \& Schau, 2005; Muniz \& 
O'Guinn, 2001). This relatively hedonic purpose for using the Internet may be subdivided into motivations for, as well as mode and manner of access, which we discuss, in turn, below.

We posit that different ethnic groups may have different motivations for why they may use the Internet, how they use the Internet once there, and face different fallouts of their Internet usage. In addition, this usage may vary depending on the extent and type of their acculturation (migrant status) as well as the extent of their existing ethnic identification. In some cases, individuals chose to abandon their socially ascribed ethnicity. Brumbaugh and Grier (2013) suggest that ethnicity may be either enduring or transitory and as such we find that those whose real-life identity projects may be of one ethnicity may choose to have a virtual ethnicity which reflects a completely different identity project. . Here, individuals may Commented [U1]: Is this your deduction on the basis of the seek out virtual rather than real ethnicity for situations in which they believe that the former work you cited or else? will make them happier or more self-actualized than the latter. For instance, many middleclass white youth in the United Status gravitate toward hip-hop culture (Dalecki 2006). In this instance, it is not a power imbalance that motivates them, but rather the sheer enjoyment of the genre and its related elements (Motley and Henderson 2008). Further, this could also be a way in which these individuals embody their own self-concept, in which they enact consumption practices that reflect a prototypical role of who they think they are (Gecas 1982; Triandis 1989).

Individuals or communities adopting these ethnically-masked and/or virtual ethnicities may exist for two reasons. First, the individual may truly want to be with fictive kin who share common interests that are not necessarily tied to the person's actual ethnicity (Ibsen and Klobus 1972). In their research of fictive kin phenomenon in the global hip-hop music diaspora, Motley and Henderson (2008) found that stigmatized individuals from various societies around the world coalesced via connective marginalities, many times using the Internet as a means of sharing music and/or lyrics, as well as other aspects of hip-hop 
culture (e.g., fashion, graffiti). Similarly, later research by Henderson and colleagues on Ian's Pizza Tribe in which individuals from Egypt found fictive kinship with protestors from Wisconsin (Henderson et al 2013, p. 284; Hunter 2011):

Thus, the members of the Ian's Pizza Tribe in Wisconsin might have had more similarity to and solidarity with their fictive kin in Egypt than they had with members of the Republican Legislature in Wisconsin, including, perhaps, some members of their own families.

There are many other online communities such as the global hip-hop diaspora and Ian's Pizza Tribe in which individuals adopt an identity other than their ethnicity in order to belong (Muniz and O'Guinn 2001). One could argue that extant work on Brand Communities such as Burning Man (Kozinets 2002), Apple Newton (Muniz and Schau 2005), and Weight Loss Support (Bradford, Grier, and Henderson 2012) all provide a means by which those of a given (or socially-constructed) ethnic identity choose a completely different identity project as their priority. However, on the flipside, this trend could lead to even more divided cultures as people would be less likely to gather new information/points of view but would instead use the Internet to reinforce what they already know/believe.

With respect to mode of access, we also find differences. For instance, AfricanAmericans have virtually leap-frogged their White-American counterparts with respect to mobile usage, particularly as a means of conducting mobile commerce (m-commerce)

(Rideout \& Wartella, 2011). One of the most exciting and powerful exchanges of information regarding the intersection of technology, media, and consumption is the annual South by Southwest (SXSW) Interactive Conference held in Austin, TX each March. In 2014, one of the most celebrated panel sessions revolved around the phenomena of "Black Twitter" which is an excellent example of the different uses and modes of access between ethnoracial
Commented [e2]: Since the references you give here are not Motley \& Henderson I suggest this rewording 
groups (cite?) What all of these have in common is that the digital divide equates to having broadband at home. It does not account for other ways of access.

The example above about Black Twitter begins to hint at the different ways in which ethnic groups may engage with the Internet regardless of the means by which they do so. Consider the idea of connective (collective) marginality such as that studied by Osumare (200x) and Motley and Henderson (2008). These studies indicate that otherwise marginalized ethnoracial groups were able to use the Internet to find similar others and connect with them on the basis of their collective marginalization in their respective cultures (e.g., North Africans in Paris, Blacks in America, Turks in Germany). Collectively, they formed a new virtual ethnicity of the Global Hip-Hop Diaspora (Motley and Henderson 2008). Henderson et al (2011) identified another virtual ethnicity of the Ian's Pizza Tribe which was based on collective political oppression.

The role and importance of these Internet forums and related sites in challenging the ethnically different inter-group beliefs and prejudices is worthy of further research. What does the Internet offer those individuals whose identity challenge the norms held by their communities and what are the well-being implications of this? To what extent do Internet video parody's, such as Asifa Lahore's Punjabi Girl, support and benefit others? Indeed, how do those outside of the target audience perceive these videos, and what are implications of this for resolving ethnic differences?

\section{Trajectory 3. Extensions of Real Life (Ethnicity in the Convergence Culture)}

As online and offline environments draw closer together ethnic minorities may encounter a convergence of their on/offline cultures. For example, Parker and Song (2006) in a study into second-generation, British-born Chinese noted how this group established 
websites to affirm a positive self-identity, addressing a wider perception of a latent collective identity amongst a geographically dispersed group. Another motivation was to affirm a positive British Chinese identity through the Internet to the wider British society. It is thus important to understand how the nature of the technological culture in which we live shapes and is shaped by our lived experience of ethnicity.

What then are the transformative benefits the Internet offers these groups? Does the Internet with its prequisite technical knowledge exclude as many members of ethnic different communities as it includes? Research is required to explore who is and isnt accessing these communities and their respective motivations.

\section{Conclusion}

Digital divide research has already established differences in the use of the Internet by different ethnic groups (Pew, 2014; Rideout \& Wartella, 2011). Though these differences have focused mainly on socioeconomic factors, they fall short in helping to understand intrinsic-based motivations to how and why these differences exist, and the importance of the Internet in constructing the self (Belk 1998; 2013). Therefore, study of (virtual) ethnicity and the Internet within the context of well-being marks a highly important line of research to further investigate. The three research trajectories mentioned here: (1) Avoidance through the use of the Internet, (2) Pursuit of Happiness (Hedonic Motivations for Virtual Ethnicity), and (3) Extensions of Real Life (Ethnicity in the Convergence Culture), are all meant to provide a fruitful starting point in this vein.

\section{References}


Askegaard, S., \& Özaglar-Toulouse, N. (2011). Still crossing borders: Migration, consumption, and markets. Consumption Markets \& Culture, 14, 217-222. doi:10.1080/10253866.2011.574823

Ayres, I. and Siegelman, P. (1995) Race and gender discrimination in bargaining for a new car. The American Economic Review: 304-321.

Berry, J.W. (1980). Acculturation as adaptation. In A.M. Padilla (Ed.), Acculturation: Theory, Models, and Some New Findings, (pp. 9-26). Boulder: Westview Press. Brumbaugh and Grier (2013)

Cohen, D. and Prusak, L. (2001) In good company: How social capital makes companies work. Harvard Business School Press, Boston, MA.

Crockett, Grier, and Williams 2003;

Dalecki, L. (2006), Kid B, Boston, MA: Houghton Mifflin, 246 pages.

Department of Culture, Media and Sport (2013) UK Broadband Impact Study: Literature Review, available at: https:/www.gov.uk/government/uploads/system/uploads/attachment_data/file/85961/UK Broadband_Impact_Study_-_Literature_Review_-_Final_-_February_2013.pdf.

Ekpo, A. E. (2012) Transcending Habitus with IT: Understanding How Marginalized

Consumers Use Information Technology. Managerial Studies. Chicago, IL: University of Illinois Chicago.

Foster, T. (2005) The Souls of Cyberfolk: Posthumanism as Vernacular Theory.

Minneapolis: University of Minnesota Press.

\section{Gecas (1982)}

Harris, Henderson, and Williams 2005;

Henderson, G. R., Guzmán, F., Huff, L. , et al. (2013) The Ian's pizza tribe:

Reconceptualizing cross-cultural research in the digital age. Journal of Business Research 
66: 283-287.

Ibsen, C.A. and Klobus, P. (1972) Fictive kin term use and social relationships: alternative interpretations. J Marriage Fam 34: 615-620.

Luna, D., \& Peracchio, L.A. (2005). Advertising to bilingual consumers: The impact of codeswitching on persuasion. Journal of Consumer Research, 31, 760-765. doi:

$10.1086 / 426609$

Molixi, L. and Bettencourt, B. A. (2010) Predicting Well-Being Among Ethnic Minorities: Psychological Empowerment and Group Identity, Journal of Applied Social Psychology, $40,3,513-533$.

Morton, F. S., Zettelmeyer F. and Silva-Risso J. (2003) Consumer information and discrimination: Does the Internet affect the pricing of new cars to women and minorities? Quantitative Marketing and Economics 1: 65-92.

Motley, C. M. and Henderson, G. R. (2008) The global hip-hop Diaspora: Understanding the culture. Journal of Business Research 61: 243-253.

Muniz, Jr. A. M. and O'Guinn, T.C. (2001) Brand community. Journal of consumer research 27: 412-432

Muniz, Jr. A. M. and Schau, H. J. (2005) Religiosity in the abandoned Apple Newton brand community. Journal of consumer research 31: 737-747.

Nandi, Alita and Platt, Lucinda (2010) Ethnic minority women's poverty and economic well being. Independent report, JN 402398. Government Equalities Office, London, UK.

Parker, D. and Song M. (2006) Ethnicity, social capital and the Internet: British Chinese Websites. Ethnicities: 6 (2): 178-202.

Rideout, V., Lauricella, A. \& Wartella, E. (2011) Children, media, and race: Media use among White, Black, Hispanic, and Asian American children. Report for the Center on Media and Human Development School of Communication Northwestern University. 
Schmitt, K. L., Dayanim, S. \& Matthias, S. Personal homepage construction as an expression of social development. Developmental Psychology 44, 496-506 (2008).

\section{Triandis (1989)}

Valkenburg, P. M. \& Peter, J. Social Consequences of the Internet for Adolescents: A Decade of Research. Curr. Dir. Psychol. 18, 1-5, doi:10.1111/j.1467-8721.2009.01595.x (2009).

Valkenburg, P. M., Peter, J. \& Schouten, A. P. Friend networking sites and their relationship to adolescents' well-being and social self-esteem. . Cyberpsychology and Behavior 9, 584-590. (2006).

Williams, J.D. and Henderson, G. R. (2011) Discrimination and Injustice in the Marketplace. Transformative Consumer Research for Personal and Collective Well-Being: 171.

Williams, Henderson, and Harris 2001

Wilson, S. (2002), Theoretical Reflections on the Digital Culture and Art, Information Arts: Intersections of Art, Science \& Technology, MIT Press: Boston. 